Supplement of Clim. Past, 15, 1099-1111, 2019

https://doi.org/10.5194/cp-15-1099-2019-supplement

(c) Author(s) 2019. This work is distributed under

the Creative Commons Attribution 4.0 License.

(c) (1)

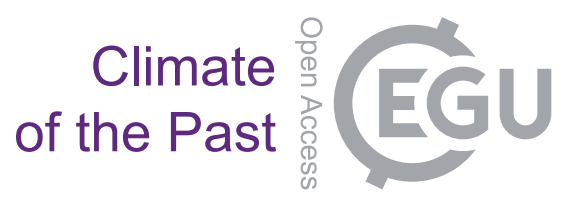

Supplement of

\title{
Long-term Surface Temperature (LoST) database as a complement for GCM preindustrial simulations
}

Francisco José Cuesta-Valero et al.

Correspondence to: Hugo Beltrami (hugo@stfx.ca)

The copyright of individual parts of the supplement might differ from the CC BY 4.0 License. 


\section{S1 Error Propagation for LoST Database}

The GIDS algorithm (Eq. 3) incorporates errors from the determination of the latitudinal, longitudinal and altitudinal gradients as well as errors from the $T_{0}$ estimates. Errors in $T_{0}$ temperatures are specified by the linear regression analysis employed to determine the $T_{0}$ values from each BTP measurement, while the linear regression analysis of the geographical distribution

5 of $T_{0}$ temperatures provides the latitudinal, longitudinal and altitudinal gradients and their errors (see Section 3). Therefore, an estimate of the error in LoST temperatures at each grid cell of the database can by computed just by applying basic error propagation theory to Eq. 3, which results in:

$\Delta V_{0}=\frac{\sqrt{\sum_{i=1}^{N}\left\{\left(\Delta V_{i}^{2}+\left(\mid \text { lat }_{0}-\text { lat }_{i} \mid \Delta C_{\text {lat }}\right)^{2}+\left(\mid \text { lon }_{0}-\text { lon }_{i} \mid \Delta C_{\text {lon }}\right)^{2}+\left(\left|z_{0}-z_{i}\right| \Delta C_{z}\right)^{2}\right)^{\frac{1}{2}}\left|d_{i}^{-2}\right|\right\}^{2}}}{\left|\sum_{i=1}^{N} d_{i}^{-1}\right|}$

where $\Delta \mathrm{V}_{0}$ is the error of the predicted temperature at the target node, $\Delta \mathrm{V}_{\mathrm{i}}$ represents the $\mathrm{T}_{0}$ error from the $\mathrm{i}^{\mathrm{th}}$ BTP measurement, $\Delta \mathrm{C}_{\text {lat }}, \Delta \mathrm{C}_{\text {lon }}$ and $\Delta \mathrm{C}_{\mathrm{z}}$ are the errors in the gradients from the regression analysis of the geographical distribution of $\mathrm{T}_{0}$ data, lat $\mathrm{t}_{\mathrm{i}}, \mathrm{lon}_{\mathrm{i}}$ and $\mathrm{z}_{\mathrm{i}}$ represent latitude, longitude and altitude of the $\mathrm{i}^{\text {th }}$ measurement respectively, lat $\mathrm{t}_{0}, \operatorname{lon}_{0}$ and $\mathrm{z}_{0}$ represent the latitude, longitude and altitude of the target node respectively, $d_{i}$ is the distance from the $i^{\text {th }}$ measurement to the target node, and $\mathrm{N}$ are the number of BTP measurements within a distance of $650 \mathrm{~km}$ to the target node. Errors in latitude, longitude and altitude are considered negligible, as well as the error in the distance between measurements and target nodes.

15 Fig. S6 shows the errors as $2 \sigma$ values (i.e., $2 \times \Delta \mathrm{V}_{0}$ ) for each grid cell, with a spatial average of $0.2{ }^{\circ} \mathrm{C}$.

Beyond the propagation of known errors, other sources of uncertainty are possible but difficult to characterize given the limited temporal resolution of the LoST database. The most probable additional source of error is the distance criterion for the interpolation. This criterion was determined using a pseudo-proxy experiment and five PMIP3/CMIP5 PM simulations, obtaining different results for each model (Fig. S1). However, we did not find any adequate method to characterize such error in the LoST database, and further sources of error are possible. Section 5 in the main text also discusses additional sources of uncertainty in LoST temperatures, but data limitations prevent us to characterize the error caused by those factors. 


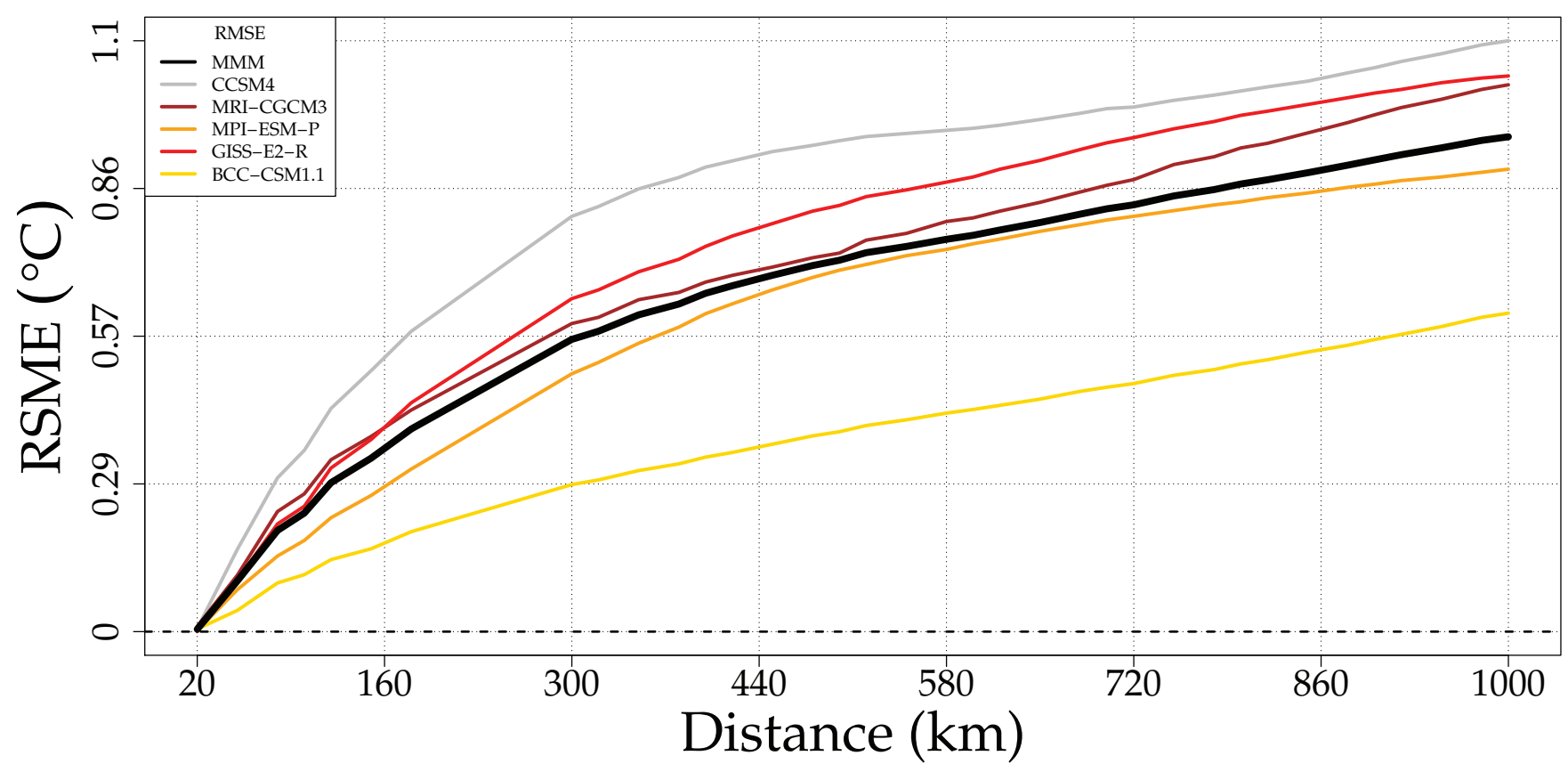

Figure S1. Root-Mean Squared Errors of the GIDS interpolation using ground surface temperatures at $1.0 \mathrm{~m}$ depth for the period $1300-1700$ CE from the PMIP3/CMIP5 PM simulations to obtain a maximum distance criterion to interpolate each BTP measurement. The black line represents the multimodel mean (MMM). 
a)

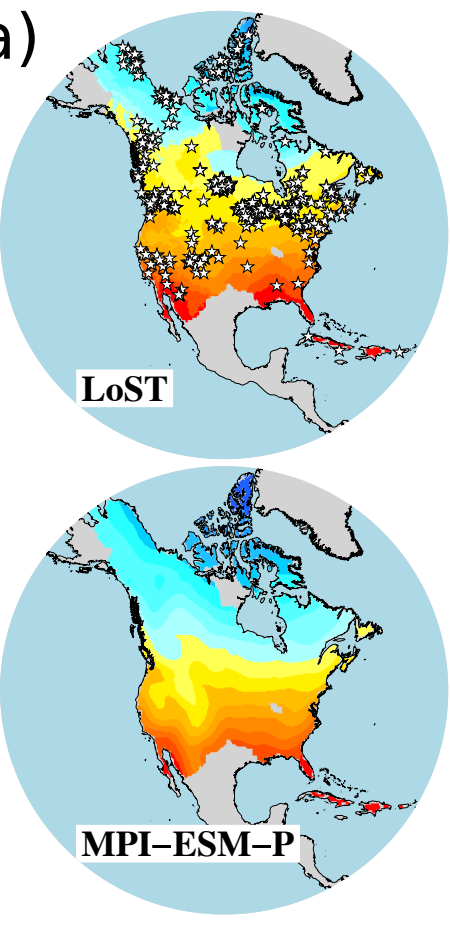

b)
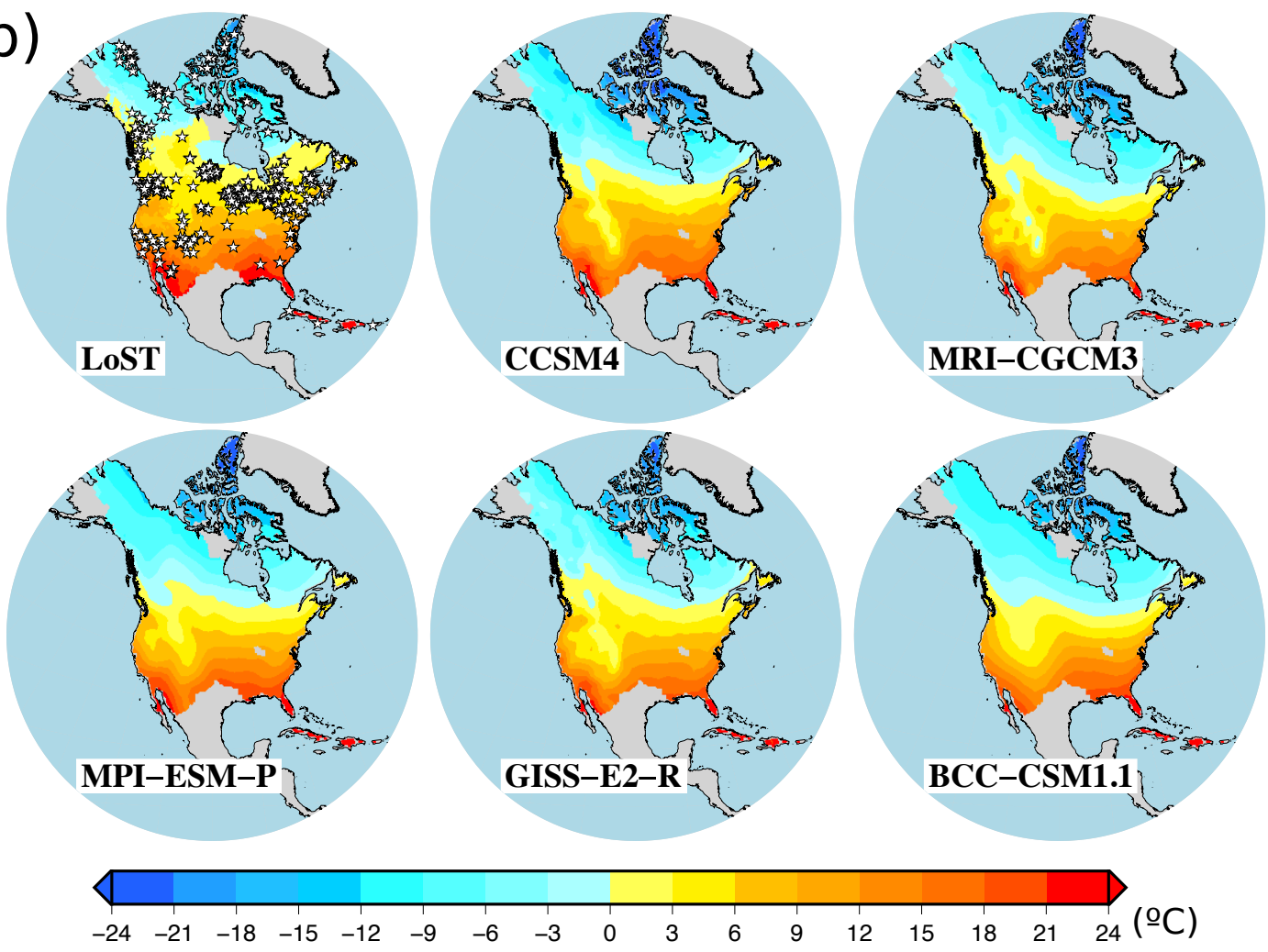

Figure S2. SAT 0 estimates from (a) PMIP3/CMIP5 PM simulations (1300-1700 CE) and (b) PMIP3/CMIP5 piControl simulations together with LoST temperatures. White stars show the location of the employed BTP measurements for the GIDS interpolation. 
a)

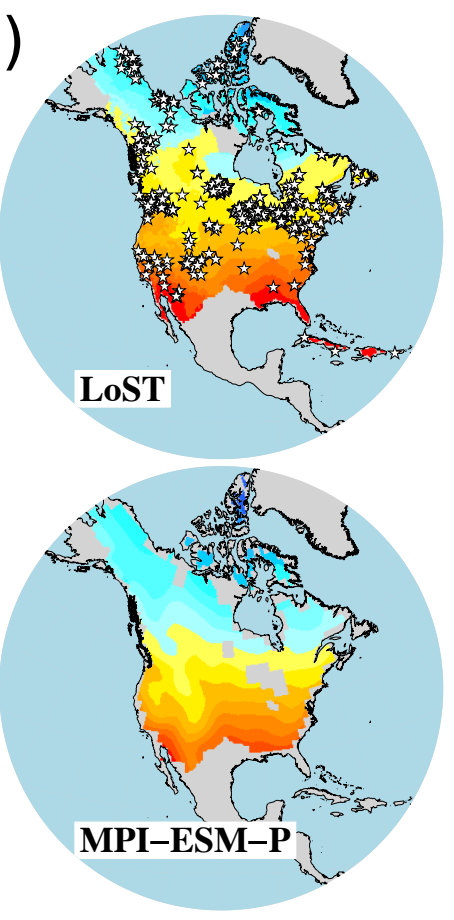

b)

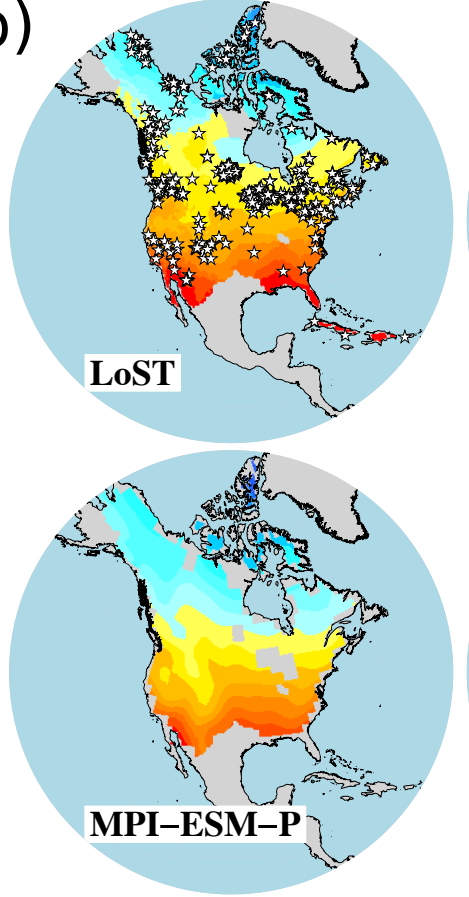

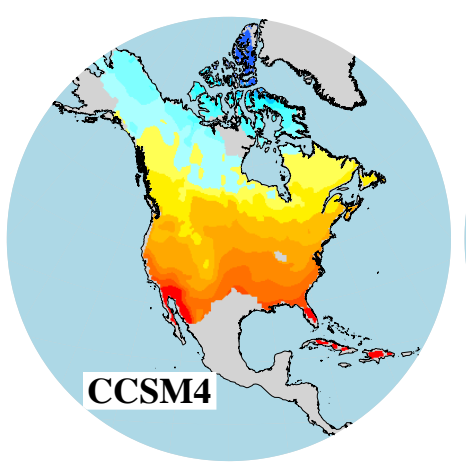
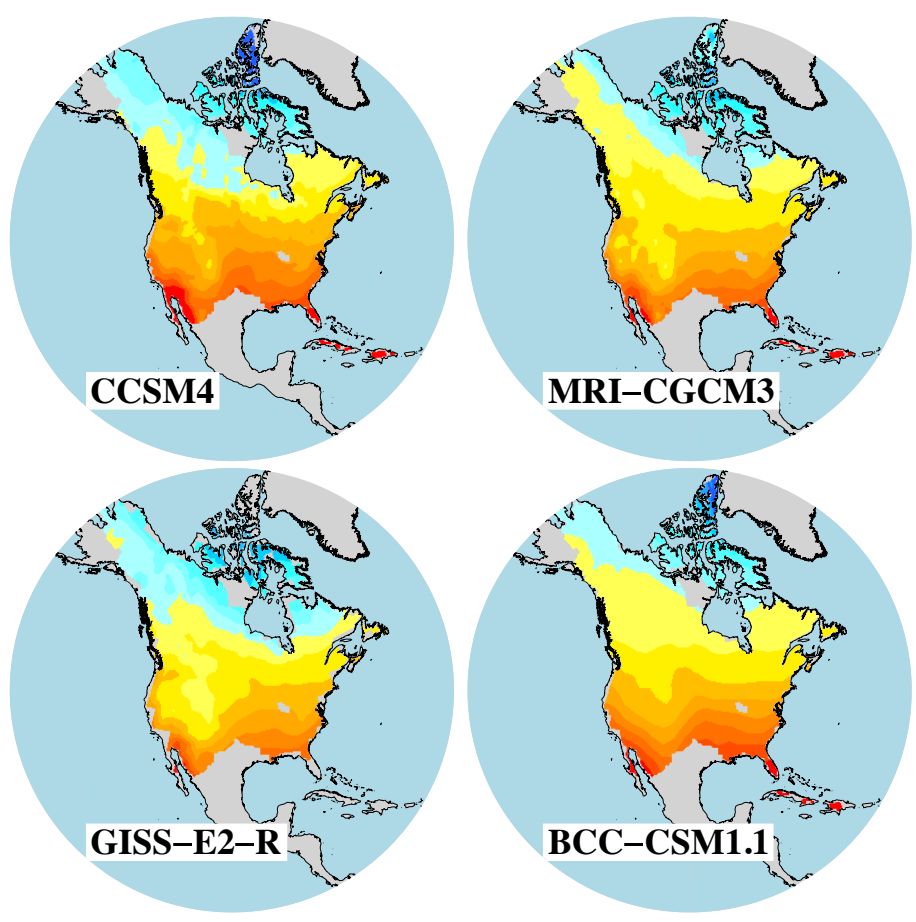
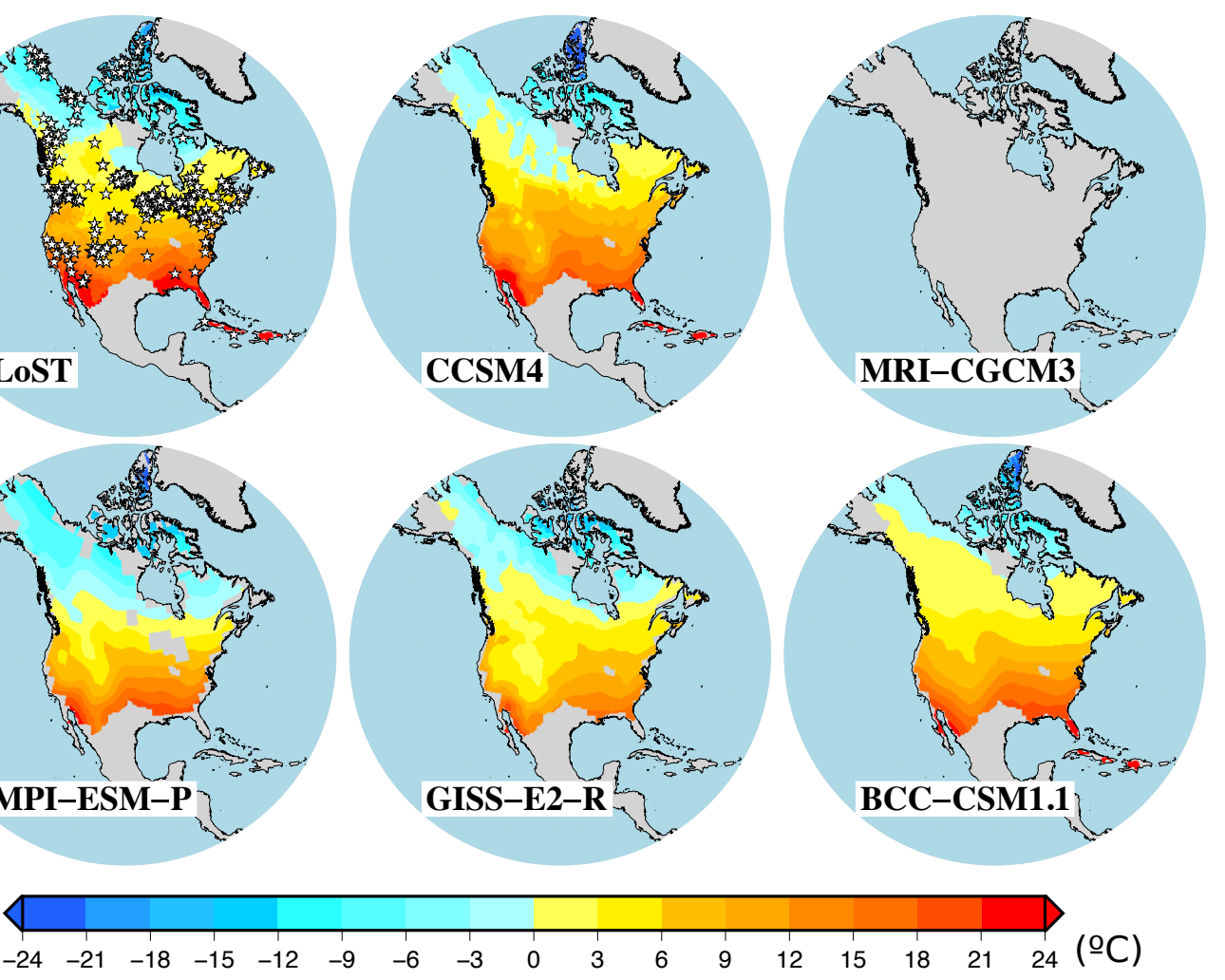

Figure S3. GST G $_{0}$ estimates from (a) PMIP3/CMIP5 PM simulations (1300-1700 CE) and (b) PMIP3/CMIP5 piControl simulations together with $\mathrm{T}_{0}$ temperatures. White stars shown the location of the employed BTP measurements for the GIDS interpolation. 

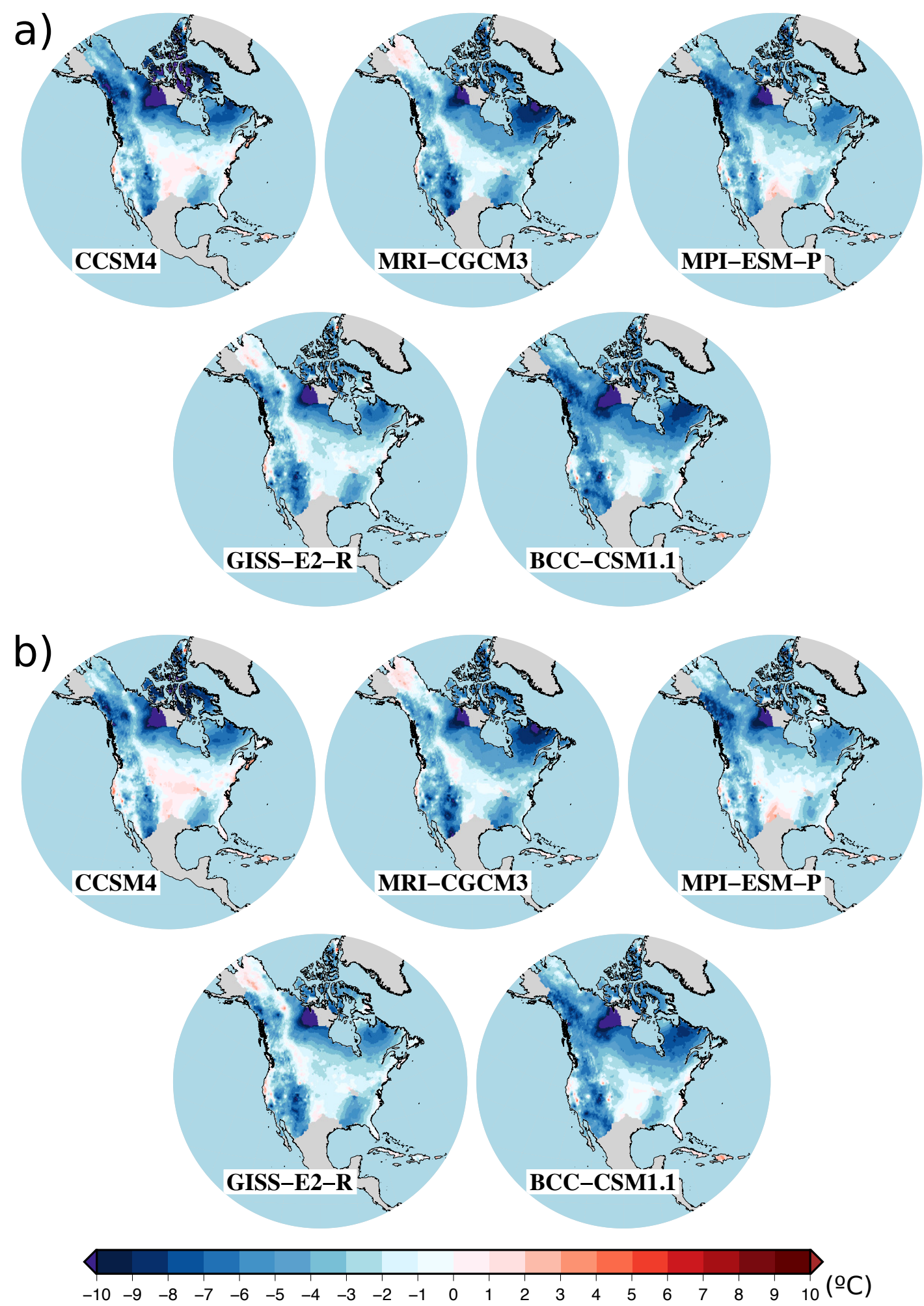

Figure S4. Difference between $\mathrm{SAT}_{0}$ values from PMIP3/CMIP5 simulations and LoST temperatures. (a) Results for PM simulations (1300-1700 CE). (b) Results piControl simulations. 

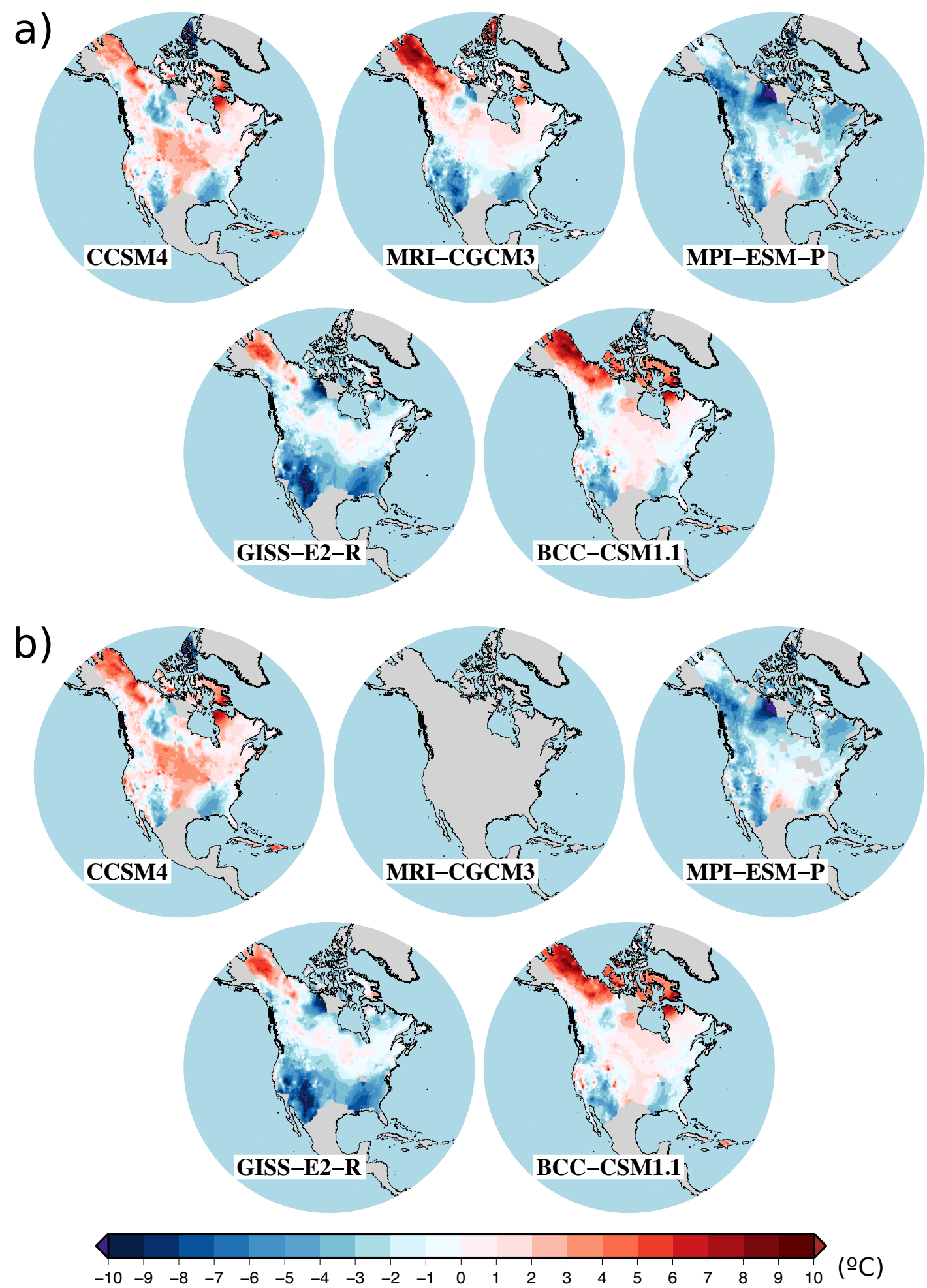

Figure S5. Difference between GST $_{0}$ values from PMIP3/CMIP5 simulations and LoST temperatures. (a) Results for PM simulations (1300-1700 CE). (b) Results for piControl simulations. 

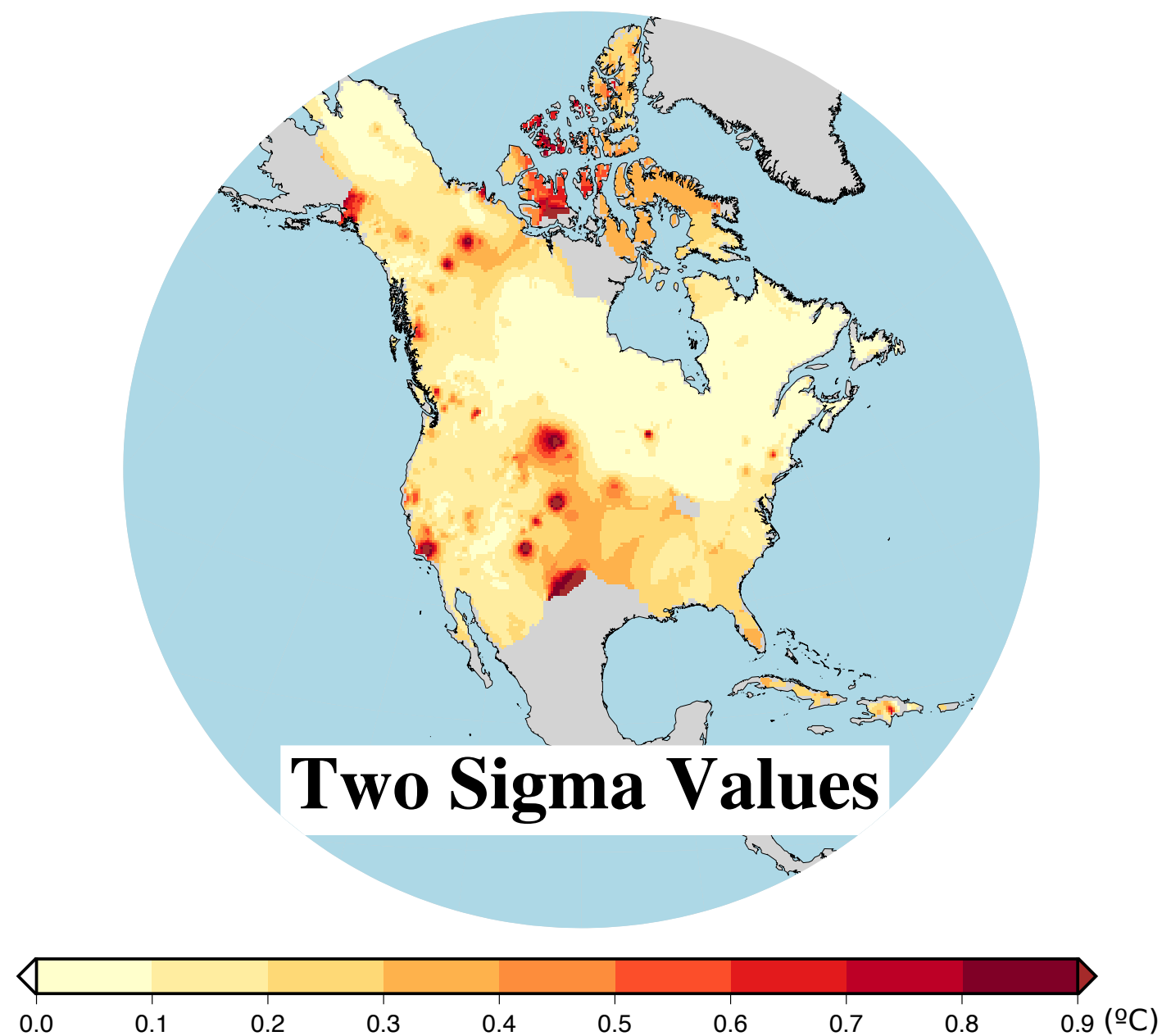

Figure S6. Errors ( $2 \sigma$ values) of LoST temperatures estimated as described in Section S1. The spatial average is $0.2{ }^{\circ} \mathrm{C}$. 

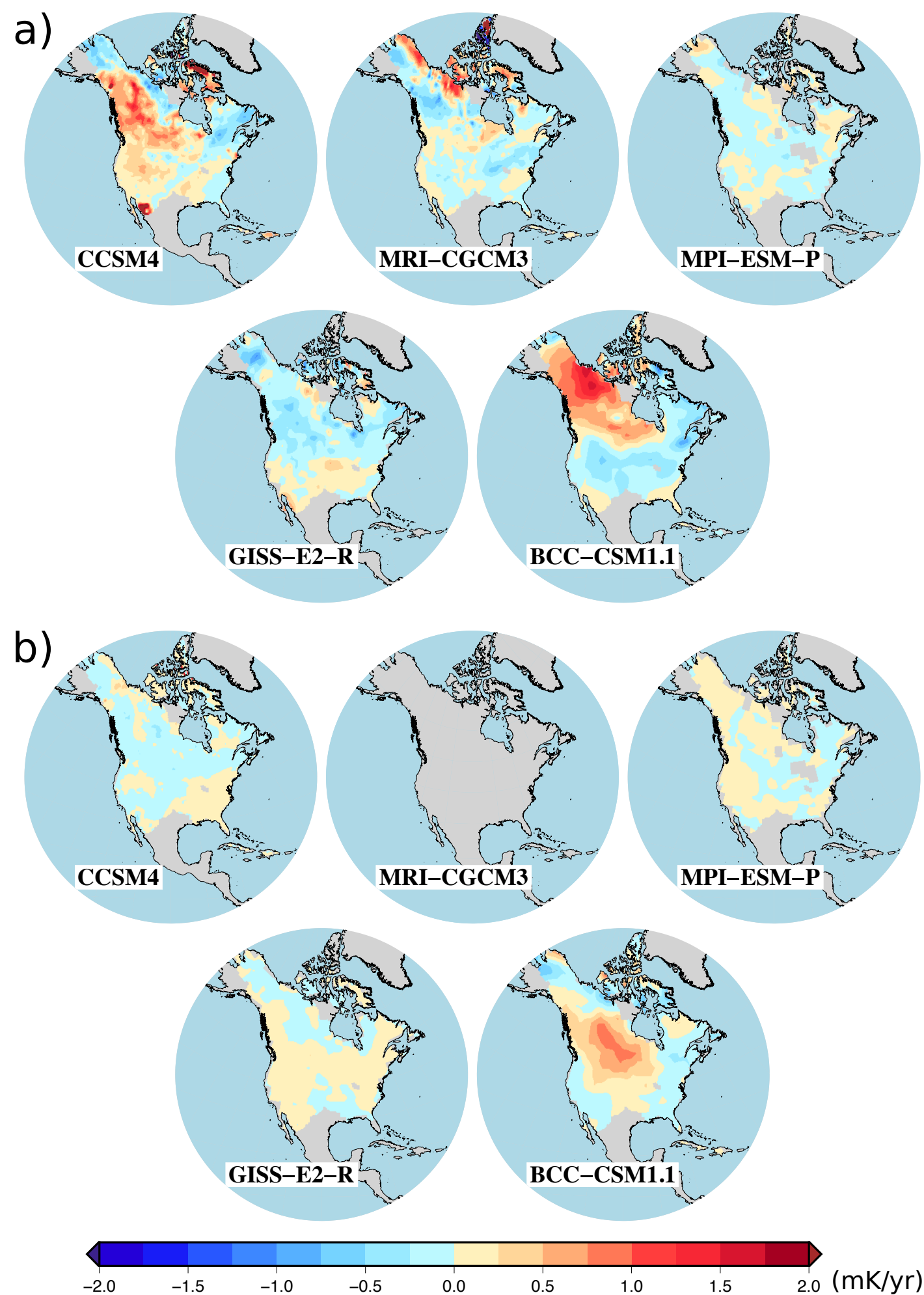

Figure S7. Trends of the difference between air and ground (1.0 m depth) temperatures from PMIP3/CMIP5 simulations. (a) Results for PM simulations (1300-1700 CE). (b) Results for piControl simulations. 


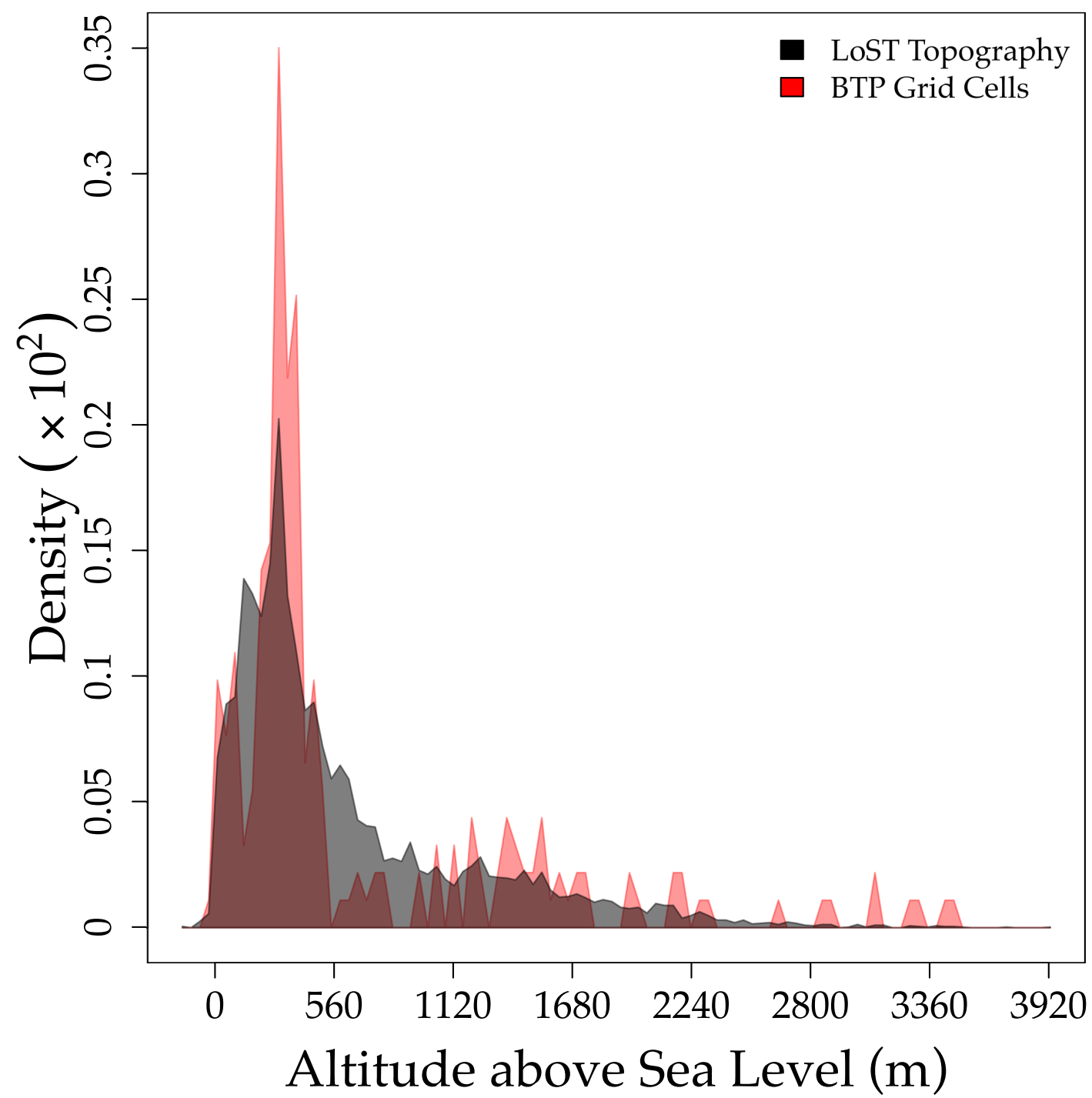

Figure S8. Altitude distribution over the LoST domain (black histogram) and at grid cells containing BTPs (red histogram) from the ETOPO2 product. 